\title{
THE PERCEIVED VALUE OF THE TEC WEEK IN THE DEVELOPMENT OF TRANSVERSAL COMPETENCES
}

\author{
Olivares $\mathrm{S}^{1^{*}}$, Turrubiates $\mathrm{M}^{1}$, Treviño $\mathrm{J}^{2}$ and Cante $\mathrm{G}^{3}$ \\ ${ }^{I}$ Tecnologico de Monterrey, Escuela de Medicina y Ciencias de la Salud, Mexico \\ ${ }^{2}$ Tecnologico de Monterrey, Escuela de Ingeniería y Ciencias, Mexico \\ ${ }^{3}$ Tecnologico de Monterrey, Vicerrectoría Académica, Mexico
}

\begin{abstract}
Currently, educational institutions have the challenge of graduating students as experts in their disciplines who have a series of competencies that will allow them to assimilate their professional identity. Tecnológico de Monterrey established the Tec Week as a mandatory framework to close the gap between academic courses and student affairs activities to develop transversal competences. Those cross-cutting competences integrate knowledge, skills, and attitudes relevant to responding, leading, and transforming an uncertain future. The present study aimed to determine the Tec Week's value in professional identity formation phases considering transversal competences There was applied a quantitative, descriptive, trans-sectional, and not experimental method. Participants were first-year students from several academic programs. A pre-test and posttest self- perception instruments were adapted from Olivares et al. (2019) to compare expectations (pre-test) from achievements (post-test) as proposed by the Expectations Confirmation Theory. Results showed that Tec Week offers development for Self-concept, Wellness and Self-awareness, Collaboration, and Diversity. The results encourage incorporating activities such as Tec Week to impact students' professional identity formation for self-care and socialization, considering an inclusive socialization environment and healthy relations during their first years.
\end{abstract}

Keywords: Professional Identity Formation, Transversal Competences, Self-concept, Selfcare, higher education

\section{Introduction}

Professional identity is the dynamic evolution of the self-concept as a person who socializes with affinity lifestyle or academic groups to perform roles within professional contexts to generate a conscious change (Olivares et al., 2020). Since the concept is dynamic, students may discover new interests, preferences, and capacities during their higher education formation. According to JarvisSelinger et al. (2012), competence and identity are present across student development, shifting one to the other. Competences are a person's ability to apply knowledge through a skill (cognitive, psychomotor, social, affective) in a specific context responding to high-quality standards (Salgado et al., 2011). Competence integrates knowledge, skills, and aptitudes to effectively perform specific responsibilities (Sá \& Serpa, 2018). There are two main types a) transversal, which can be applied in any situation or task, and b) disciplinary related to the technical part of students' career choice. Martínez Clares and González Morga (2017) define them as a social and professional need, accepted to manage and react to change and employability. Competency-based education indicates that those can be formed longitudinally through the curriculum (Martínez Clares and González Morga, 2017). 
As the students demonstrate competence through particular tasks, they eventually assimilate the professional's identity from who executes those tasks (Jarvis-Selinger et al., 2012). Unlike the implicit assumptions of constant (perhaps even linear) progression in competency-based training, professional identity formation theory remarks the evolution into new identity stages. Curricular changes that support professional identity formation include activities that engage students in the development of their own identities, providing a range of welcoming communities that facilitate their entry (Cruess et al., 2019). Full participation in a community of practice enables the learners to construct their identities through engagement, experimentation, collaboration, and contribution with other group members (Clegg et al., 2009). Then, higher education institutions should promote identity formation as part of the university experience.

There are blurring boundaries in conceptions between curricular and extracurricular education, so there is a lack of stable or explicit of what contents should be formalized on university programs (Clegg et al., 2010). Sports, dance, and community services have been traditionally conceptualized as extracurricular activities (ECA) at the university level. According to Clegg et al. (2010) there is evidence that students' participation in extracurricular activities benefits graduates' employability and other outcomes as wellbeing and personal development. However, the increasing range of activities that students may participate outside the academic courses creates tension for selection and prioritization, especially for newcomers. The "extra" tag name has forcefully separated academic courses from wellbeing activities segregating the student formation with plural identities with different values instead of one single journey. Disciplinary and formal curricular credits are always on the top of the student agenda, ignoring the importance of self-care, socialization, and exploration to decide a career choice.

\section{Tec Week at Tecnologico de Monterrey}

Tecnológico de Monterrey designed bachelor programs that cleared curricular spaces for personal and professional development to reconcile the tension between extracurricular activities and curricular courses. The Tec Week is a mandatory total immersion learning approach that invites students to be introduced to several potential identities considering activities of:

- Introspection and reflection to discover talents and interests for deep individual selfknowledge.

- Physical activation or cultural appreciation for the development of habits towards integral wellbeing.

- Recognition of the other to establish empathic and inclusive relationships for the construction of agreements.

- Social impact on establishing commitments aimed at undertaking transformation actions.

- Disciplinary workshops to reinforce the construction of a professional conceptualization

Each activity is carefully designed to develop specific transversal competences four times a year during the week 6 and 12 of a regular semester. There is no other academic conflicting schedule for students to focus on their personalized aspirations, cultural capital, and fitness during the Tec Week. Even that it does not have credits, it is mandatory to assist students as they chart progress towards becoming a professional. 
Tec Weeks integrate learning into the curriculum to reinforce career and life competences (IFC, 2019). Employers highly value transversal competences since they facilitate self-confidence, interpersonal interaction, and problem-solving, among other capacities (Buckley \& Lee, 2018). For Tec Week four out seven competences were included on the Tec Week as presented in table 1 (IFC, 2019).

Table 1: Tec 21 Transversal competences for Tec Week

\begin{tabular}{|c|c|c|}
\hline Classification & Description & Competences \\
\hline $\begin{array}{l}\text { Self-concept and Self- } \\
\text { management }\end{array}$ & $\begin{array}{l}\text { Builds a personal and professional } \\
\text { wellbeing plan throughout life, through } \\
\text { responsible reflection, and the integration } \\
\text { of emotional and intellectual resources }\end{array}$ & $\begin{array}{c}\text { Self-awareness } \\
\text { Wellbeing and self-care }\end{array}$ \\
\hline Social intelligence & $\begin{array}{l}\text { Generates environments that are effective } \\
\text { for collaboration and negotiation in } \\
\text { multicultural contexts that are respectful } \\
\text { and appreciative of a diversity of people, } \\
\text { knowledge, and cultures }\end{array}$ & $\begin{array}{l}\text { Collaboration } \\
\text { Negotiation } \\
\text { Diversity }\end{array}$ \\
\hline Innovative entrepreneurship & $\begin{array}{c}\text { Generates innovative and versatile } \\
\text { solutions in changing environments that } \\
\text { create value and have a positive impact on } \\
\text { society }\end{array}$ & $\begin{array}{c}\text { Innovation } \\
\text { Conscious entrepreneurship }\end{array}$ \\
\hline $\begin{array}{l}\text { Ethical and citizenship } \\
\text { commitment }\end{array}$ & $\begin{array}{l}\text { Implements projects oriented to the } \\
\text { transformation of the environment and } \\
\text { common welfare with an ethical } \\
\text { conscience and social responsibility }\end{array}$ & $\begin{array}{l}\text { Recognition and empathy } \\
\text { Citizenship commitment }\end{array}$ \\
\hline
\end{tabular}

At Tecnológico de Monterrey, it was implemented the i-Week, once a year since 2015. I-Week helped to understand the professional identity growth during the academic program in four phases: Selfknowledge, Affinity relationships, Conceptualization, and Conscious change. A cross-comparison among classes shown that i-Week influences the professional identity since older cohorts refer to have a better understanding of their professional role through three identity stages: Self-knowledge, Professional conceptualization, and Conscious change $(\mathrm{N}=1,583$, p-value $<0.05)$ (Olivares et al., 2020). The figure 1 compares competences with professional identity formation phases: 


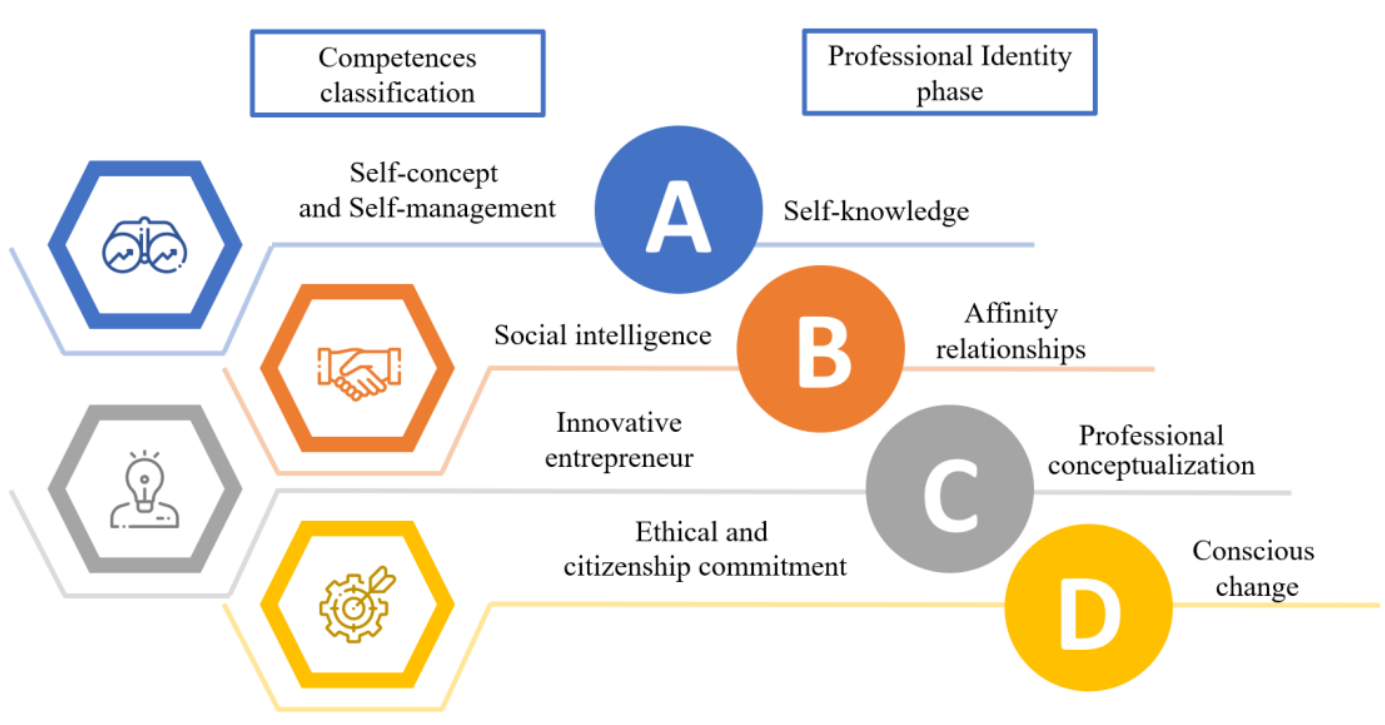

Figure 1. Professional identity formation phases associated with competence classification.

Since 2019, the i-Week was transformed into the Tec Week. The new design increased the number of weekly experiences from 1 to 4 . This approach incorporated some strategies to have a more profound impact on professional identity and competency development. Previous research from i-Week showed competency development on problem-solving, innovation, critical thinking, intellectual curiosity, among others (Olivares et al., 2019).

\section{Objective}

The present study aimed to determine the Tec Week's value in professional identity formation phases considering transversal competences.

A description of the professional identity formation phases and the competences associated with each stage are described in the following paragraphs.

\section{1) Self-knowledge}

The professional identity phase of Self-knowledge proposed by Olivares et al. (2020), implies that the individual has clarity about their values and preferences about the present and the future. According to the authors, this stage includes selecting a professional pathway based on a deep understanding of the personal capacities and opportunities, considering a short, medium, and long-term plan based on a sense of independence. This is associated with the Self-concept and Self-management classification. According to Kulakow (2020) self-concept is a multidimensional construct that refers to an individual evaluation of personal cognitive abilities in academic achievement contexts. The support of competence tends to result in increasing levels of motivation, academic performance, and wellbeing.

Self-awareness: For Tecnológico de Monterrey (2019) defines this competence as the capacity to define a self-concept based on an ethical framework, a self-assessment, and continuous critical reflection oriented to personal and professional development. Self-awareness is an essential element for the development of personal and professional wellbeing (National Academies of Sciences, 
Engineering, and Medicine, 2019). According to Drolet and Rodgers, (2010), spaces for selfawareness should be promoted as one of the spheres of wellbeing.

Wellbeing and self-care: Tecnológico de Monterrey (2019) refer to systematically implement appropriate strategies of physical, emotional, mental, and economic self-care to interiorize wellbeing and professional self-care gradually. Personal and professional wellbeing should be promoted at higher education institutions from systemic, interpersonal, and individual interventions during the years of academic training (Shanafelt et al., 2019).

\section{2) Affinity relationships}

The professional identity phase of Affinity relationships described by Olivares et al. (2020) refers to students participating in associations, academic networks, and other social groups related to their individual personal or professional interests. These interpersonal relationships within a program contribute to establishing formal or informal learning communities that could become friends or future networks. This is associated with the social intelligence classification. According to Busowon (2017) social intelligence is the ability to act sensibly in human relations, sometimes it is called people skills.

Collaboration: According to Tecnológico de Monterrey (2019), the student with this competence builds agreements and interactions through collaboration that considers differences among personal abilities and those from others. In the educational context, collaboration involves the integration of knowledge, skills, attitudes, and values in a specific situation required to contribute with the team (Eizagirre et al., 2017). Considering extracurricular activities, participants identified teamwork as a skill significantly developed (Buckley \& Lee, 2018).

Diversity: According to Tecnológico de Monterrey (2019), a graduate should respect diversity according to the human rights fundamentals. Diversity focuses on the person's characteristics, such as sex, age, religion, or social condition that represent different ways of thinking of people. Diversity as competence should be addressed in higher education to generate collective learning and creativity in problem-solving (Corritore et al., 2020).

Negotiation: The student generates results and commitments in the groups in which he participates, through collaborative work, decision-making, and the generation of value (Tecnológico de Monterrey, 2019). According to Page and Mukherjee (2009) the negotiation process has three parts: planning, real negotiation, and subsequent negotiation. Taylor et al. (2008) list various strategies for successful negotiation, for example finding win-win solutions, listening to the other side, and evaluating the best alternatives to negotiated agreements.

\section{3) Professional conceptualization}

According to Olivares et al. (2020), Professional conceptualization refers to the possibility of actively participating in a work context and being accepted within the community of practice to develop activities that are only delegated to knowledgeable people in the area. This is associated with Innovative entrepreneurship classification. According to Wellalage et al., (2021) innovative entrepreneurship contributes to job development, uplifting communities and stimulating positive social change in developing economies. 
Innovation: According to Tecnológico de Monterrey (2019), creative students generate innovative and valuable solutions to complex problems through a cyclical process of continuous learning in positive and adverse situations. For Obviagbonhia et al. (2019), innovation competence is the capacity to develop creative ideas that can be implemented successfully as projects, products, services that are perceived as valuable or meaningful to the intended audience.

Conscious entrepreneurship: The student evaluates entrepreneurial initiatives' impact in the personal context and other interest groups considering an ethical framework (Tecnológico de Monterrey, 2019). The new educational focus is to understand that business and projects should be forced for good (sustainability and social impact) and practice human-centered design thinking (Linda Parris \& McInnis-Bowers, 2017).

\section{4) Conscious change}

Conscious change refers to the person's formation towards adding value by leading changes for society, considering multiple perspectives creatively and sustainably (Olivares et al.,2020). This is associated with Ethical and citizenship commitment classification. According to Arshad et al. (2021), ethics and citizenship contributes to leadership through actions and interpersonal relationships through communication and decision-making to impact society.

Recognition and empathy: According to Tecnológico de Monterrey (2019), the student who has this competence respects the dignity, rights, contributions, and circumstances, personal and others, trying to present constructive and supportive solutions to other people's situations. Empathy refers to the ability to need to understand or feel what another person is experiencing or to be able to locate oneself in its context (Donnelly et al., 2019).

Citizenship commitment: The student builds committed, sustainable and supportive solutions to social problems through strategies that strengthen democracy and the common good (Tecnológico de Monterrey, 2019). Today's society requires citizens committed to creating changes that favor social wellbeing considering a democratic and inclusive culture Cox et al. (2005).

\section{Methods}

\section{Design}

There was applied a mixed design to combine the advantages of qualitative and quantitative approaches. The quantitative design consists in a pre and post-test applied to measure the perceived value of the students. From the qualitative approach, an open question is analyzed. The scope of the study is transectional because the data is collected in a single moment Hernández et al. (2010).

\section{Instruments}

The methodology used for instrument design is proposed by Fisher et al. (2001) with the following phases: 1) design instruments as a pre-test and post-test based on transversal competences, 2) validation by experts and improvement of the items; 3 ) statistical validation. 
1) Design of the Tec Week self-reflection instruments

Two self-reflection questionnaires were designed as a pre-test and post-test surveys to be applied before and after the Tec Week. The designed questionnaires were adapted from Olivares et al. (2020). The pre-test helps to identify the expectations and preferences of the students before Tec Week. The post-test aims to identify the achievements obtained during Tec Week that favor the development of the transversal competences of the Tec21 Model. The items are stratified according to the Tec21 Model (table 1). The comparison between the pre-test and post-test results generates the perceived value of the students. Items included both qualitative and quantitative answers.

2) Validation by experts and improvement of items

Each item was reviewed, discussed, and analyzed by eight professors who belong to the sports, cultural instructors, and the Business School. A focus group methodology was performed considering y Savin-Baden and Howell Major (2013) proposal. The ideas from participants were documented, and inconsistencies were highlighted.

\section{3) Statistical validation.}

Internal consistency and reliability of both the pre-test and the post-test in its final version was computed with Cronbach's alpha coefficient. According to Vogt (2007) a value greater than 0.70 is satisfactory for most of the cases. For this case, the pre-test had a Cronbach's alpha of 0.93 and the post-test, 0.97, which is considered favorable.

\section{Participants}

This study aimed to determine the Tec Week's perceived value for transversal competence learning during the first semester of its implementation. Participants in the study accepted to answer pre-test and post-test voluntarily. The questionnaires were applied from October 28 to November 1, 2019, to182 first-semester students from diverse academic programs. A 1 to 5 Likert scale was used from Totally disagree to Totally agree

\section{Data collection and analysis}

The results were categorized using the Expectations Confirmation Theory as shown in figure 2. The theory compares expectations with perceived value to obtain three possible categories: + DC (Positive Deconfirmation) with a positive difference with a value above the expectations, C (Confirmation) where expectations are met and -DC (Negative Deconfirmation) as negative variation against expectations (Yue-Yang et al., 2010). For the present study, the quantitative result compares the means between pre-test and post-test and is coded as (+ DC) Exceeds expectations, (C) Meets expectations, and (-DC) Below expectations. Categories + DC or $-\mathrm{DC}$ apply only with a significant difference between pre-test and post-test ( $\mathrm{p}$-value $<0.05$ ). 


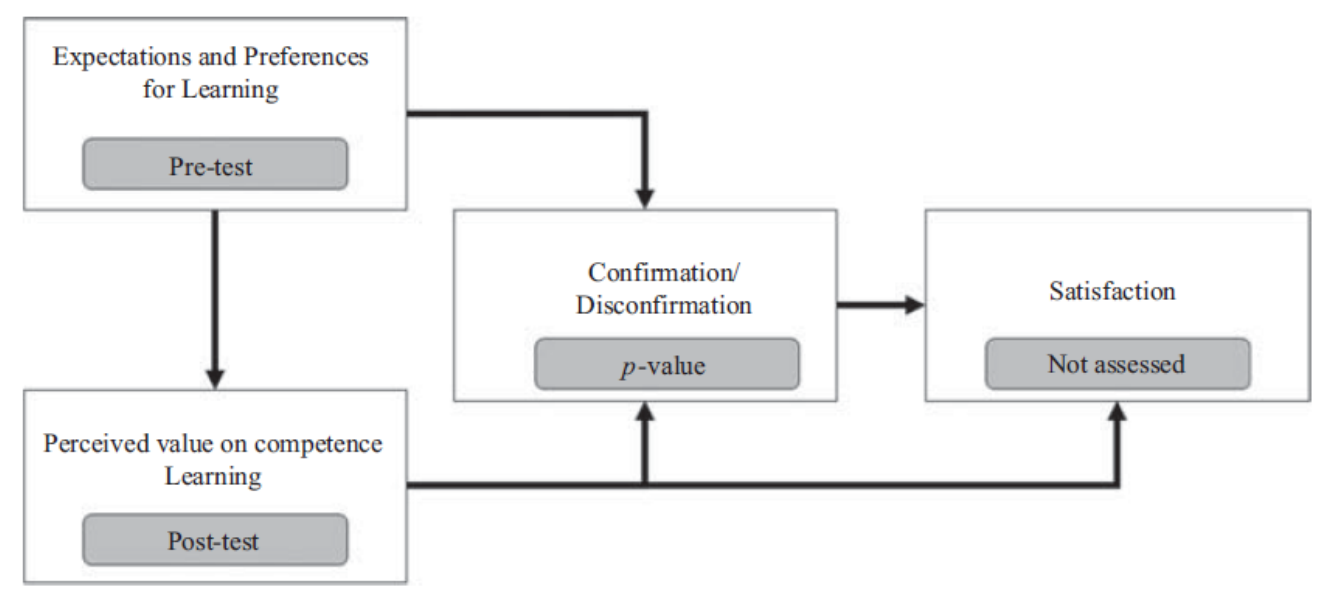

Figure 2. Expectation Confirmation Theory Model (Olivares et al., 2019)

Quantitative results were analyzed using the Wilcoxon test to identify significant differences in the students' perception between the pre-test and the post-test. Qualitative results were gathered with the post-test survey with the question: What did you learn in Tec Week? Answers were categorized by identity formation phases: Self-knowledge, Affinity relationships, Professional conceptualization, Conscious change. A text analysis of the students' responses was performed to obtain the necessary data to build a deep understanding (Hanson et al., 2011).

\section{Results}

Several activities that used to exist as extracurricular or informal opportunities were considered to be formalized as part of the Tec Week to address transversal competences by design, including some academic elements, as instructional schedule and assessment. Transversal competences that exceeded expectations were: Self- awareness, Collaboration, Negotiation effectiveness, and Recognition and empathy (table 2). The earlier approach at Tecnologico de Monterrey, similar to the TecWeek was the i-Week, also proved transversal competences learning. The action learning design from the i-Week helped to develop self-directed learning, intellectual curiosity, critical thinking, problem-solving, teamwork, and innovation (Olivares et al., 2019).

Table 2: Results from Expectation Confirmation Theory

\begin{tabular}{cccccc}
\hline $\begin{array}{c}\text { Professional } \\
\text { identity phase }\end{array}$ & Competence & $\begin{array}{c}\text { Average pre- } \\
\text { test }\end{array}$ & $\begin{array}{c}\text { Average post- } \\
\text { test }\end{array}$ & $\begin{array}{c}\text { P- } \\
\text { value }\end{array}$ & ECT code \\
\hline $\begin{array}{c}\text { Self- } \\
\text { knowledge }\end{array}$ & $\begin{array}{c}\text { Self-awareness } \\
\text { Wellbeing and self- } \\
\text { care }\end{array}$ & 3.01 & 4.08 & $0.03 *$ & $\begin{array}{c}\text { Above expectations } \\
(+\mathrm{DC})\end{array}$ \\
\hline $\begin{array}{c}\text { Affinity } \\
\text { relationships }\end{array}$ & $\begin{array}{c}\text { Collaboration } \\
\text { Diversity }\end{array}$ & 3.92 & 3.69 & 0.99 & Met expectations (C) \\
\hline Negotiation \\
effectiveness
\end{tabular}




\begin{tabular}{cccccc}
$\begin{array}{c}\text { conceptualizati } \\
\text { on }\end{array}$ & $\begin{array}{c}\text { Conscious } \\
\text { entrepreneur }\end{array}$ & 4.25 & 3.54 & 1.00 & Met expectations (C) \\
\hline $\begin{array}{c}\text { Conscious } \\
\text { change }\end{array}$ & $\begin{array}{c}\text { Recognition and } \\
\text { empathy } \\
\text { Citizenship } \\
\text { commitment }\end{array}$ & 3.71 & 3.98 & $0.00^{*}$ & $\begin{array}{c}\text { Above expectations } \\
(+D C)\end{array}$ \\
\hline
\end{tabular}

These results for i-Week showed similarities and differences with Tec Week. Collaboration is a competence developed above expectations in both experiences. Innovation was formed in i-Week (+DC), but only met expectations in Tec Week (C). Citizenship commitment met expectations in both studies.

From the 182 students, only 139 open answers were considered as valid for the purpose of the study, as part of the qualitative analysis. Table 3 show the results.

Table 3: Qualitative results

\begin{tabular}{|c|c|c|c|}
\hline $\begin{array}{l}\text { Professional } \\
\text { identity phase }\end{array}$ & Competence & Quantity & Examples of comments \\
\hline \multirow{2}{*}{ Self-knowledge } & Self-awareness & \multirow{2}{*}{25} & $\begin{array}{l}\text { "I learned that emotions play a very important role in } \\
\text { our lives, and that it is very important to know how to } \\
\text { recognize them and express them in a good way" }\end{array}$ \\
\hline & $\begin{array}{l}\text { Wellbeing and } \\
\text { self-care }\end{array}$ & & $\begin{array}{c}\text { "The importance of exercising, eating healthy, having } \\
\text { good habits and in the same way I learned more about } \\
\text { the value of resilience" }\end{array}$ \\
\hline \multirow{3}{*}{$\begin{array}{l}\text { Affinity } \\
\text { relationships }\end{array}$} & Collaboration & \multirow{3}{*}{41} & $\begin{array}{l}\text { "I learned to work with a team and support each other. } \\
\text { I learned to stop feeling ashamed, to show my face and } \\
\text { to always make an effort" }\end{array}$ \\
\hline & Diversity & & $\begin{array}{l}\text { "Inclusion, respect for those who are different from } \\
\text { me, that there is diversity and the true meaning of } \\
\text { tolerance throughout history" }\end{array}$ \\
\hline & $\begin{array}{l}\text { Negotiation } \\
\text { effectiveness }\end{array}$ & & \\
\hline \multirow{2}{*}{$\begin{array}{c}\text { Professional } \\
\text { conceptualization }\end{array}$} & Innovation & \multirow{2}{*}{32} & $\begin{array}{l}\text { "I learned about the needs of people with limited } \\
\text { resources, I learned to look for alternative solutions } \\
\text { accessible to them" }\end{array}$ \\
\hline & $\begin{array}{l}\text { Conscious } \\
\text { entrepreneur }\end{array}$ & & $\begin{array}{l}\text { "I learned how I can launch a project with a purpose } \\
\text { that is not only something personal, but can have a } \\
\text { positive impact on society" }\end{array}$ \\
\hline \multirow[t]{2}{*}{ Conscious change } & $\begin{array}{c}\text { Recognition and } \\
\text { empathy }\end{array}$ & 12 & $\begin{array}{l}\text { "I learned to accept people as they are and to feel } \\
\text { identified with people who do not have everything and } \\
\text { that we must support them since we often do not value } \\
\text { things and we must have the ability to help them." }\end{array}$ \\
\hline & $\begin{array}{l}\text { Citizenship } \\
\text { commitment }\end{array}$ & & $\begin{array}{l}\text { "I learned to have empathy towards others, to change a } \\
\text { little my thinking and perspective towards the things } \\
\text { and people around me" }\end{array}$ \\
\hline
\end{tabular}




\section{Discussion}

Qualitative and quantitative results have consistent results for Self-Knowledge and Affinity relationships. The following discussion includes examples that describe the connection between some activities with the presented results.

\section{Self-Knowledge}

During the Tec Week "Introspective Journey", each student established a self-concept, describing their life history through self-assessment, using personal ethics. This opportunity for reflection and group sharing in a safe space represents a pause moment to establish self-awareness. It is also a moment to understand an individual past to construct a short, medium, and long-term plan as part of the Self-knowledge professional identity phase. According to Clegg et al. (2009), extracurricular activities have demonstrated relieving stress and tension or general wellbeing on the students.

\section{Affinity relationships}

During the Tec Week "Theater with meaning", students prepared proposals to address an innovative solution for social problems to enhance awareness in their contexts. They prepared a play to introduce and solve the problem. A combination of drama skills and instructional design led the teamwork to collaborate for a common purpose. They also applied negotiation skills to decide each member's role, materials, and script. Both collaboration and negotiation are important interpersonal skills useful to to construct a community of practice. According to Clegg et al. (2009), a community of practice forge the identity of those who participate within it, build relationships, and give members a sense of affinity.

During the Tec Week "Me, you, others, us", students were able to identify human rights and diversity interacting with people in a wheelchair and with down syndrome. Students experimented themselves how to live on those conditions in simulations and role modeling practices. The week helped the students to promote an empathetic relationship with people with diverse requirements. According to Buckley and Lee (2018), students are impacted by their actions and skills when they acquire the ability to contribute to a larger community for altruistic reasons.

Quantitative and qualitative results are inconsistent in the last two phases: professional conceptualization and conscious change. A possible explanation is that activities included mixed purposes. For example, "Entrepreneur with a purpose", and "Frugal innovation" were oriented to apply disciplinary knowledge to benefit vulnerable groups. According to Clegg et al. (2009) there are no clear boundaries between the formal or informal curriculum. While the formal curriculum is restricted in mind considering classroom teaching by academics, extracurricular has been considered as work developed by the staff. Since the students require competencies for life, higher education institutions are responsible for forming those skills for employability, no regarding the delivery format.

\section{Conclusion}

Competence-based education and professional identity formation require a different approach to learning. The Tec Week closes the gap from curricular vs. extracurricular. Innovation and entrepreneurship, which used to be rigorous academic courses, were transformed into an enjoyable 
and fun experience. Some no longer "extra" curricular activities as drama classes or sports are being introduced as part of the formal program with an assigned schedule, assessment, and competence educational objectives, which resembles a traditional course.

The presented study has as limitation that is transactional and the results are from self-perception from the students. Further research should include a longitudinal approach to understand the value of the Tec Week on the professional identity formation. Since the Tec Week introduces students to several activities, maybe in the future they might actually engage in identities as entrepreneurs, leaders or athletes among others. Students have the opportunity to decide which activity from a pool of possibilities that also include community service, first aid, dance, and leadership workshops, among others.

The COVID-19 changed the instructional delivery format for TecWeek into a remote and digital distance experience. Further studies will also address the TecWeek perceived value under the new circumstances. The show must go on.

\section{Acknowledgments}

The authors would like to acknowledge the financial support of Writing Lab, TecLabs, Tecnologico de Monterrey, Mexico, in the production of this work.

\section{References}

Arshad, M., (2021). Impact of prosocial motivation on organizational citizenship behavior: the mediating role of ethical leadership and leader-member exchange. Quality and Quantity, 55(1), 133-150. doi.org/10.1007/s11135-020-00997-5.

Buckley, P., \& Lee, P. (2018). The impact of extracurricular activity on the student experience. Active learning in higher education, 1-12. doi: 10.1177/1469787418808988

Busowon, T. (2017). Social Intelligence and Communication Competence: Predictors of Students' Intercultural Sensitivity. English Language Teaching, 10(2), 136-149. doi: 10.5539/elt.v10n2p136

Clegg, S., Stevenson, J., \& Willott, J. (2009). Extending conceptualisations of the diversity and alue of extracurricular activities: a cultural capital approach to graduate outcomes. Project Report. Higher Education Academy. Obtenido de http://eprints.leedsbeckett.ac.uk/id/eprint/850/

Clegg, S., Stevenson, J., \& Willott, J. (2010). Staff conceptions of curricular and extracurricular activities in higher education. Higher Education, 59, 615-626. doi: 10.1007/s10734-009-9269-y

Corritore, M., Goldberg, A., Srivastava, S. (2020). Duality in diversity: How intrapersonal and interpersonal cultural heterogeneity relate to firm performance. Administrative Science Quarterly, 65(2), 359-394.

Drolet, B. \& Rodgers, S. (2010). A Comprehensive Medical Student Wellness Program-Design and Implementation at Vanderbilt School of Medicine. Academic Medicine, 85(1),103-110.

Donnelly, S. Razavy, S., Levett-Jones, T. (2019). Measuring the impact of an interdisciplinary learning project on nursing, architecture and landscape design students' empathy. PLOS ONE: 14(10).

Eizagirre Sagardia, A., Altuna Urdin, J., \& Fernández Fernández, I. (2017). Prácticas de éxito en el desarrollo de competencias transversales en centros de Formación Profesional del País Vasco. revista española de pedagogía, 293-308. 
Fisher, M., King, J., y Tague, G. (2001). Development of a self-directed learning readiness scale for nursing education. Nurse Education Today, 21, 516-525.

Hernández, R., Fernández, C., \& Baptista, P. (2010). Metodología de la Investigación. México: McGraw Hill.

IFC. (2019). Breaking Paradigms to Develop Leaders for the 21st Century. International Finance Corporation: World Bank Group.

Jarvis, S., Pratt, D., Regher, G. Competency is not enough: integrating identity formation into the medical education discourse. Academic Medicine, 87(9), 1185-1190. doi: 10.1097/ACM.0b013e3182604968.

Kulakow, S. (2020). Academic self-concept and achievement motivation among adolescent students in different learning environments: Does competence-support matter? Learning and Motivation, 70(1). doi:10.1016/j.lmot.2020.101632.

Linda Parris, D., \& McInnis-Bowers, C. (2017). Business Not as Usual: Developing socially conscious entrepreneurs and intrapreneurs. Journal of Management Education, 41(5), 687-726. doi: $10.1177 / 1052562917720709$

Martínez Clares, P. y González Morga, N. (2017). Las competencias transversales en la universidad: propiedades psicométricas de un cuestionario. Transversal competences at university: psychometric properties of a questionnaire. Educación XX1, 21(1), 231- 262. doi: 10.5944/educXX1.20194.

National Academies of Sciences, Engineering, and Medicine. (2019). Taking action Against Clinician Burnout: A Systems Approach to Professional Well-Being. The National Academies Press, doi: $10.17226 / 25521$.

Olivares, S. L., Adame, E., Treviño, J. I., López, M. V., \& Turrubiates, M. L. (2019). Action learning: challenges that impact employability skills. Higher Education, Skills and Work-Based Learning, 10(1): 203-216. doi: 10.1108/HESWBL-07-2019-0097

Olivares, S. L., Rivera, N., López, M. V., \& Turrubiates, M. L. (2020). Etapas de la identidad para ser profesionista: evolución de las expectativas de los retos académicos a lo largo de la carrera. Formación Universitaria, 13(4), 11-20. doi:10.4067/S0718-50062020000400011

Ovbiagbonhia, A. R., Kollöffel, B., \& den Brok, P. (2019). Educating for innovation: students' perceptions of the learning environment and of their own innovation competence. Learning Environments Research, 22, 387-407 (2019). doi:10.1007/s10984-019-09280-3

Page, D., y Mukherjee, A. (2009). Effective technique for consistent evaluation of negotiation skills. Education, 129(3), 521-533.

Sá, M. J., \& Serpa, S. (2018). Transversal competences: Their importance and learning processes by higher education students. Education Sciences, 8(126). doi:10.3390/educsci8030126

Salgado, F., Corrales, J.,Muñoz, L., y Delgado, J. (2011). Diseño de programas de asignaturas basados en competencias y su aplicación en la Universidad de Bío-Bío, Chile . Revista Chilena de Ingeniería, 20 (2), 267-268.

Shanafelt, T., Trockel, M., Ripp, J., Murphy, M., Sandborg, C., Bohman, B. (2019). Building a Program on Well-Being: Key Design Considerations to Meet the Unique Needs of Each Organization. Academic Medicine, 94(2), 156-161.

Savin-Baden, M., y Howell Major, C. (2013). Qualitative research. Theessential guide to theory and practice. Madrid: Routledge Interactive.

Taylor, K. A., Mesmer-Magnus, J., \& Burns, T. M. (2008). Teaching the art of negotiation: Improving students' negotiating confidence and perceptions of effectiveness. Journal of Education for Business, 83(3), 135-140.

Tecnológico de Monterrey. (2019). Competencias transversales: Una visión des del Modelo Educativo. Documento guía para el docente de educación superior. 
Vogt, W. (2007). Quantitative research methods for professionals. Bos-ton, MA: Pearson/Allyn and Bacon.

Wallage, N., Hunra, A., Manita, R., Locke, S. (2021). Information communication technology and financial inclusion of innovative entrepreneurs. Technological Forecasting and Social Change, 163(1), 1-13. doi: $10.1016 / j$.techfore.2020.120416 